\title{
ANATOMICAL FEATURES OF BONES AND BONY CAVITIES OF THE OSTRICH SKULL (STRUTHIO CAMELUS)
}

\author{
Attia A.A. Moselhy ${ }^{* 1}$, Sherif Kh. A. Mohamed ${ }^{2}$, Hanaa M. El-Ghazali ${ }^{3}$. \\ ${ }^{* 1}$ Lecturer of Anatomy and Embryology, Faculty of Veterinary Medicine, Zagazig University, Egypt. \\ ${ }^{2}$ Lecturer of Anatomy and Embryology, Faculty of Veterinary Medicine, Zagazig University, Egypt. \\ ${ }^{3}$ Lecturer of Anatomy and Embryology, Faculty of Veterinary Medicine, Zagazig University, Egypt. \\ ABSTRACT
}

Background: The morphology of ostrich skeleton was meager rather than fowl for which already a lot of literature is available. This work attempts to present different views of skull bones of ostrich.

Materials and Methods: The present research was carried out on ten heads of adult ostriches. The obtained heads were collected from different ostrich slaughtered houses at Alexandria. The preparations of bones were performed by maceration technique. Two head was radiographed at Surgery Department, Faculty of Veterinary Medicine, Zagazig University.

Results: Ostrich skull consists of two parts; neurocranium and splanchnocranium which are separated by two large orbital cavities. Neurocranium is composed of single bones (occipital, sphenoid, ethmoidal) and paired (temporal, parietal and frontal) bones. The splanchnocranium consists of single bones (mandible, vomer and hyoid bones) and paired (quadrate, lacrimal, nasal bone, premaxilla, maxilla, Zygomatic (jugal), palatine bone and pterygoid) bones.

Conclusion: A significant result was obtained in this work that, there are variations in shape and components of ostrich skull bones in comparison with other birds. The similarity to small domestic birds was almost near to duck and geese rather than fowl and pigeon skulls. Also, there are some variations with large birds like an emu.

KEY WORDS: Morphology, Neurocranium, Splanchnocranium and Radiograph.

Address for Correspondence: Dr. Attia A.A. Moselhy, Department of Anatomy and Embryology, Faculty of Veterinary Medicine. Zagazig University, Egypt. Zagazig University, El-zeraa street. 114; 44511-zagazig; Egypt Tel: 01147618235 Fax: 020552283683. E-Mail: atiaanatomy@gmail.com

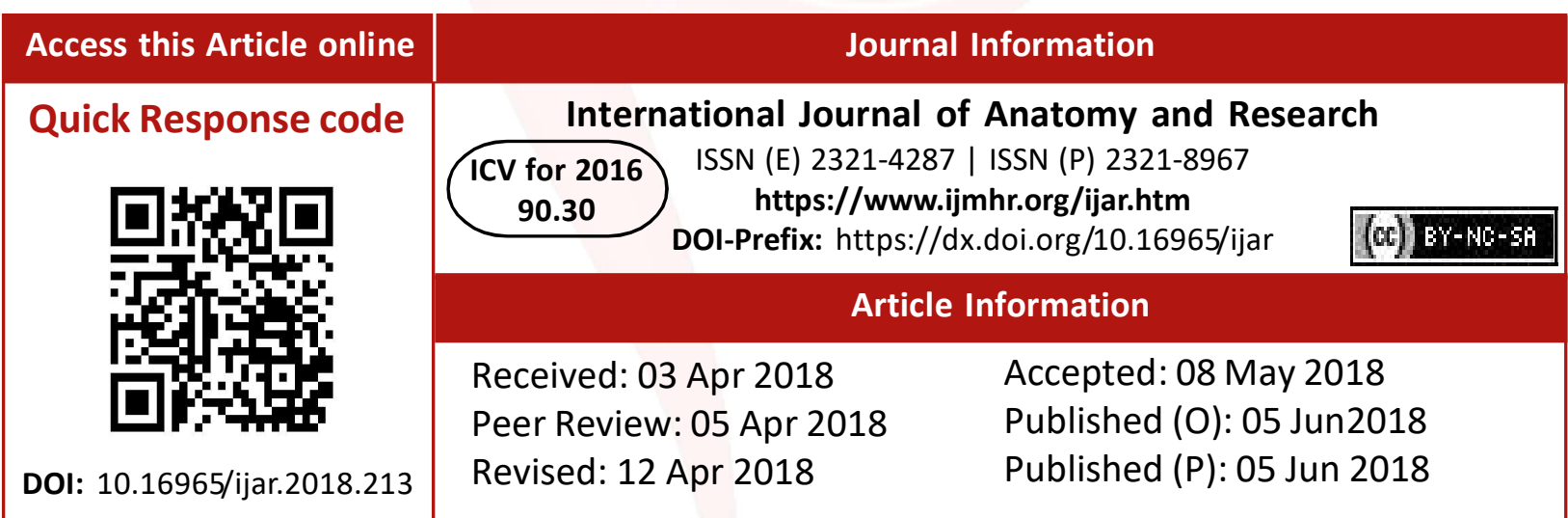

\section{INTRODUCTION}

Ostrich belongs to the family; Struthioidae, genus Struthio, species Camelus called (Struthio camelus). It is of high economic value, as its meat is toothsome, loose and highly nutritive, and also it has pliable, permeable and highly durable leather, so it is considered as the highest grade leathers as well as high quality of feathers [1, 2].

Recently, In Egypt, the pathological affections in ostrich have been increased. Therefore, the anatomists focus their studies on the morphology of this bird and the anatomy of the ostrich has become an important challenge for researchers and practitioners. From this point of view, the demand of the osteological features of the appendicular and axial skeleton in ostrich has been developed [3].

The morphology of ostrich skeleton was meager rather than fowl for which already a lot 
of literature is available. This work attempts to present different views of the ostrich skull bones, which can be discussed to clear and increase the availability of literature on other domestic birds. The present work highlighted on the macro-anatomy of the ostrich skull and the structural details of different bones. Ostrich is flightless bird has many anatomical characters. The current investigation may be helpful to veterinary anatomists and surgeons to plan future researches.

\section{MATERIALS AND METHODS}

The present research was carried out on ten heads of adult apparently healthy slaughtered ostriches of both sexes (from two to three years). The obtained heads were collected from different ostrich slaughtered houses at Alexandria. Eight specimens were used to study the osteological features of the ostrich skull. Immediately after slaughter, soft tissues and brain were removed from the heads, then were put in a 5\% potassium hydroxide solution for one day under observation for maceration and remnants of the soft tissue were cleaned. The bones were immersed in a solution of hydrogen peroxide $10 \%$ for thirty minutes. After this time, the bones were exposed to running water and the parts were dried in the sun for two days this according to $[4,5]$. The obtained skulls were photographed using a Sony digital camera, 16.1 MP, 4x and images were processed on the computer. Two heads were radiographed dorsoventrally and laterally to illustrate the different bony limitations of the ostrich skull in different views at Surgery Department, Faculty of Veterinary Medicine, Zagazig University. Mobile Fischer X-ray machine H.G. Fischer, inc. Franklin Park, Illinois, USA, with maximum output of $125 \mathrm{k} . \mathrm{V}$ and 100 to $300 \mathrm{MA}$ and POX -BT 300 (Toshiba rotanode). The denominations of the bony structures followed the recommendations of [6].

\section{RESULTS}

Ostrich skull is appeared pyramidal in shape with narrow flat rostral apex and wide large rounded caudal base. Most bones of the ostrich skull are pneumatic especially vomer, temporal, sphenoid and parietal bones. It composes of two components; neurocranium (the bones of the cranium) and splanchnocranium (the bones of the face) $x$
Ostrich skull is appeared pyramidal in shape with narrow flat rostral apex and wide large rounded caudal base. Most bones of the ostrich skull are pneumatic especially vomer, temporal, sphenoid and parietal bones. It composes of two components; neurocranium (the bones of the cranium) and splanchnocranium (the bones of the face) which are discrete by two orbital cavities. Neurocranium is composed of single bones (occipital, sphenoid, ethmoidal) and paired (temporal, parietal and frontal) bones.

The splanchnocranium consists of single bones (mandible, vomer and hyoid bones) and paired (quadrate, lacrimal, nasal bone, premaxilla, maxilla, Zygomatic (jugal), palatine bone and pterygoid) bones (Figs 1,2,3,4).

The occipital bone is situated basally and formed from three parts; base (basioccipitale), paired lateral (exooccipitale) and squamous part (supraoccipital) which is surrounded a rounded Foramen magnum. Just rostral to Foramen magnum there is a hemispherical single occipital condyle. The supraoccipital part represents the caudal thick aspect of the cranial cavity which separated from the parietal bone, dorsally by nuchal crest and has a median external occipital protuberance. The basal part is divided into two depressed fossae by raised area and is separated from basisphenoid by a transverse ridge. The paired lateral part is protruded, forming a broad like process (paraoccipital process) that demarcates the external acoustic meatus, caudally and is attached distally by a ligament to the articular part of the mandible. Hypoglossal Foramen is situated medial to the latter broad process (Figs 3,4,5,6).

The sphenoid bone is formed the major thickest pneumatic part of the floor of the cranium. It is divided into caudal basisphenoid and rostral presphenoid parts. Basisphenoid has a body and two temporal wings. Basisphenoid form the rostral boundary of external auditory meatus and rostromedially, it has a foramen of the auditory tube. Presphenoid constitutes of a median body, two orbital wings and two rostolateral large bar like processes (parashenoid wings) (about 1.5 $\mathrm{cm}$ in length). The latter process is articulated with pterygoid bone. Orbital wings connected medially with interorbital septum (Figs 3,4,6,7). The ethmoidal bone has horizontal and vertical 
Fig. 1: Dorsal view of ostrich skull showing: Os parietale (op), Os frontale (of), Proc. Frontalis (pff), Proc. Lacrimalis (pl), Os lacrimale (ola), Os nasale (ona), lateral nasal process (Inp), Os premaxillare (opr), Proc. Maxillaries (pma), Proc. Frontalis (pfp), Os maxillare (oma), Os jugale (oj), Proc. jugalis (pjm) and Proc. Quadratojugale (pqj).

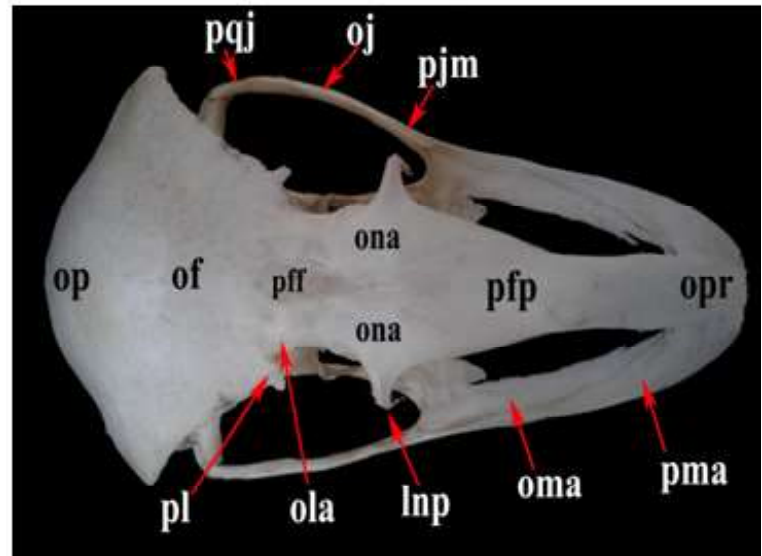

Fig. 2: Radiographic image of ostrich head (lateral view) showing: Os parietale (op), Os frontale (of), Os lacrimale (ola), Os nasale (ona), Proc. Frontalis (pfp), Corpus ossis premaxillare (cop), Proc. Maxillaries (pma), Os jugale (oj), Foramen opticum (fop) Cavum cranii (cc), orbita (o) and Cavum nasi (cn).

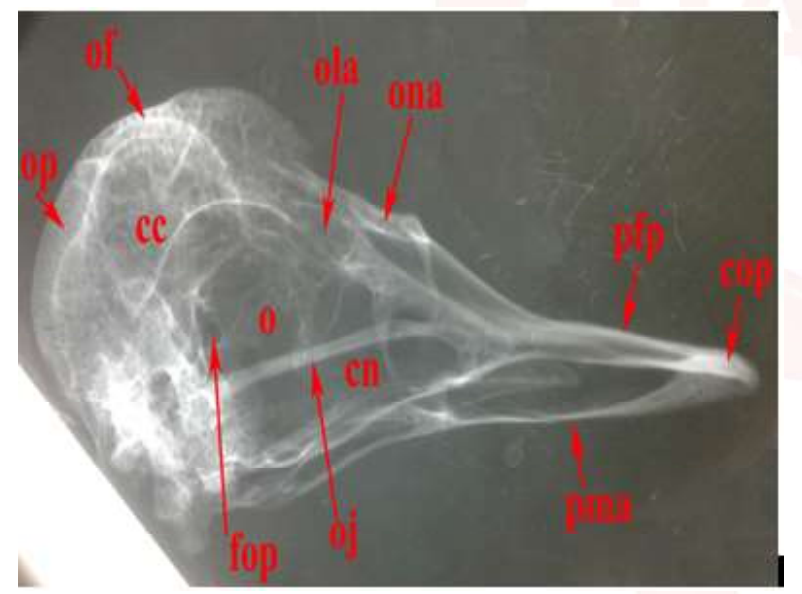

Fig. 3: Ventral view of ostrich skull showing: Os premaxillare (opr), Vomer (v), Os sphenoidale (osp), Os basioccipitale (obo), Os maxillare (oma), Sinus frontalis (sf), Os pterygoideum (opt), Os quadratum (oq), Ossa otica (oot), Os exoccipitale (oex), Condylus occipitalis (co), Foramen tuba auditiva (fta), Os jugale (oj) and Os palatinum (opa).

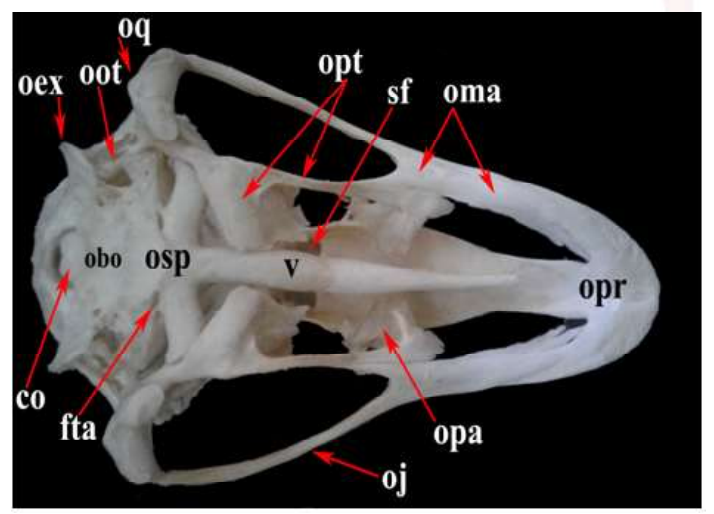

Fig. 4: Radiographic image of ostrich head (ventrodorsal view) showing: Os supraoccipitale (os), Foramen magnum ( $\mathrm{fm})$, Condylus occipitalis (co), Os quadratum (oq), Proc. quadratojugale (pqj), Proc. jugalis jugale (pjj), Proc. jugalis (pjm), lateral nasal process (Inp), Proc. Palatinus (ppa), Proc. Maxillaries (pma), Corpus ossis premaxillare (cop), Os maxillare (oma), Pars horizontalis ethmoidale (phe), Os palatinum (opa), Vomer (v), Sinus frontalis (sf), Os pterygoideum (opt) and Os sphenoidale (osp).

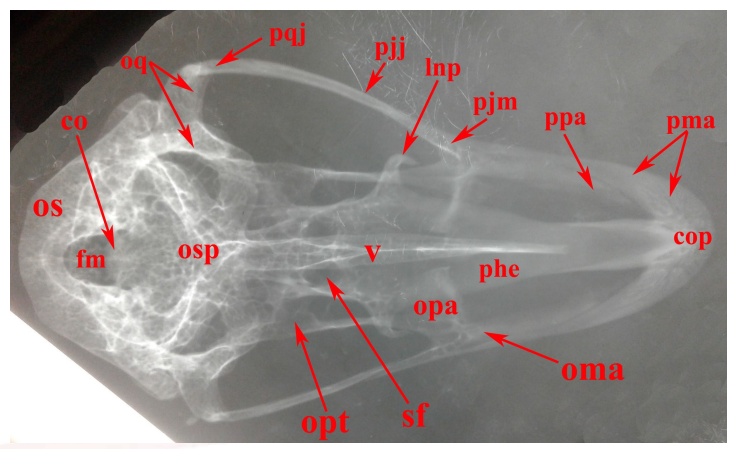

Fig. 5: Caudal view of ostrich skull showing: Os supraoccipitale (os), Foramen magnum (fm), Os exoccipitale (oex), Os basioccipitale (obo), Condylus occipitalis (co), Proc. postorbitalis (ppo), Proc. zygomaticus (pz), Proc. mandibularis (pmq), Condylus medialis (cme), Condylus lateralis (cla), Proc. oticus (pot) and Canales n. hypoglossi (cnh).

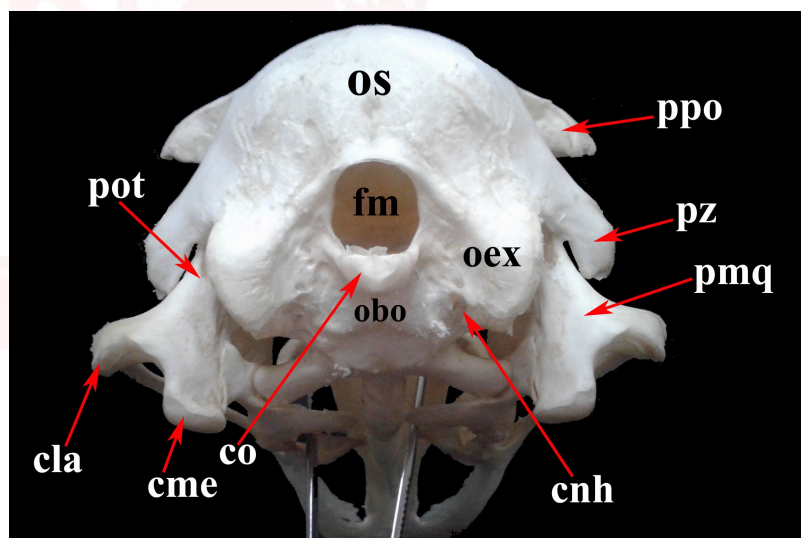

Fig. 6: Ventral view of ostrich skull (caudal aspect) showing: Foramen magnum ( $\mathrm{fm}$ ), basioccipitale (obo), Os basisphenoidale (obs), Ala parasphenoidalis (ap), Ala temporalis (at), Os supraoccipitale (os), Canales n. hypoglossi (cnh), Proc. zygomaticus (pz), Proc. oticus (pot), Condylus medialis (cme), Condylus lateralis (cla), Proc. quadraticus (pqt), Pars palatina (ppp), Os pterygoideum (opt), corpus ossis quadrati (coq), Ossa otica (oot) and Os exoccipitale (oex).

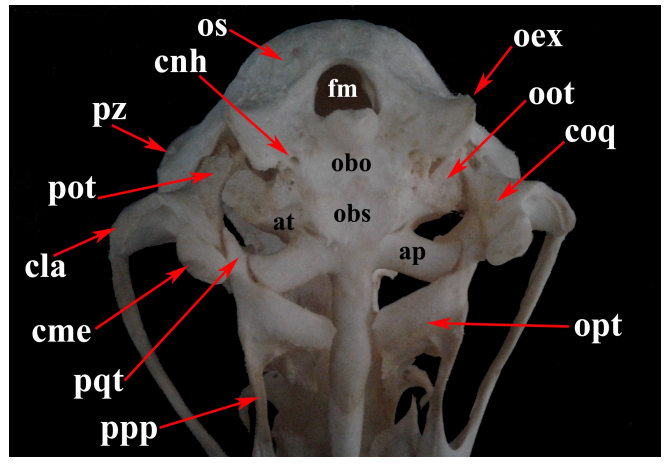



SKULL (STRUTHIO CAMELUS).

Fig. 7: Paramedian view of ostrich skull showing: Os supraoccipitale (os), Os parietale (op), Os frontale (of), Sinus frontalis (sf), Pars horizontalis ethmoidale (phe), Proc. premaxillaris (ppm), Pars verticalis ethmoidale (pve), Foramen opticum (fop), Foramen n. Ophthalmici (fnop), Foramen maxillomandibularis ( $\mathrm{fxm})$, Condylus occipitalis (co), Canales n. hypoglossi (cnh), Meatus acusticus internus (mai), Fossa cerebralis ( $\mathrm{fcl}$ ), Fossa cerebellaris (fcll), Septum interorbitale (si), Septum nasi osseum (sno), Os basisphenoidale (obs) and Vomer (v).

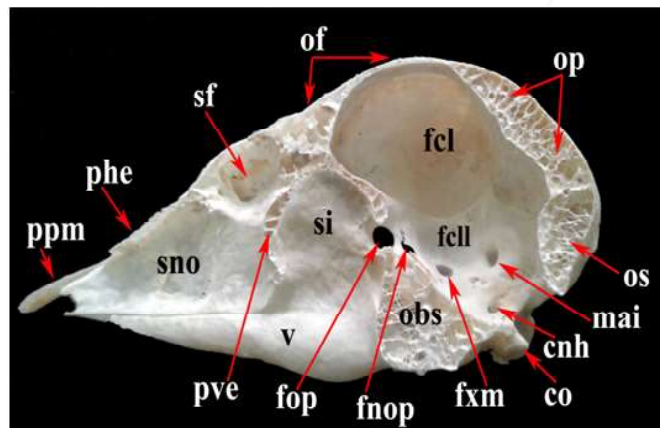

Fig. 8: Lateral view of ostrich skull showing: Os premaxillare (opr), Proc. Frontalis (pfp), Proc. Maxillaries (pma), lateral nasal process (Inp), Pars verticalis ethmoidale (pve), Os maxillare (oma), Proc. jugalis maxillare (pjm), Os pterygoideum (opt), Proc. jugalis jugale (pjj), Proc. orbitalis (por), Proc. quadratojugale (pqj), Os exoccipitale (oex), foramen maxillomandibularis ( $\mathrm{fmm}$ ), Os parietale (op), Fossa temporalis ( $\mathrm{ft}$ ), Proc. postorbitalis (ppo), Foramen $\mathrm{n}$. Ophthalmici (fnop), Os frontale (of), Foramen n. Cochlearis (fnc), Foramen orbitonasale (fon), Foramen opticum (fop), Septum nasi osseum (sno) and Orbita (o).

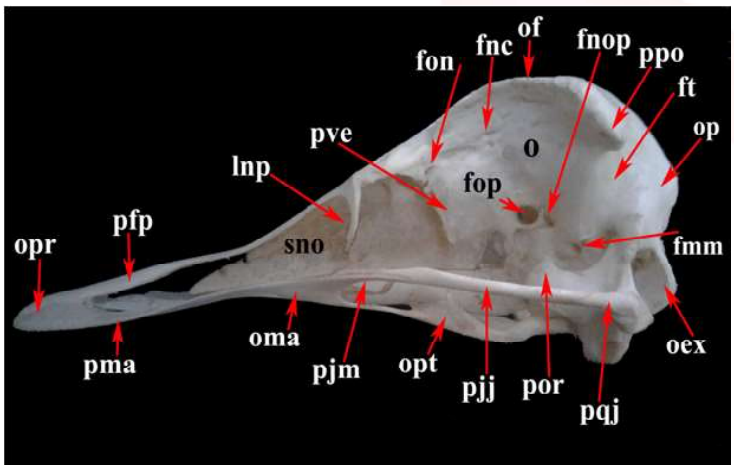

Fig. 9: Ventral view of ostrich skull (rostral aspect) showing: Os palatinum (opa), Pars horizontalis ethmoidale (phe), Corpus ossis premaxillare (cop), Proc. Maxillaries (pma), Proc. Palatinus (ppa), Proc. Frontalis (pfp), Proc. Premaxillaris (ppx), Proc. jugalis (pjm), Pars pterygoidea (ppt) and Sinus frontalis (sf).

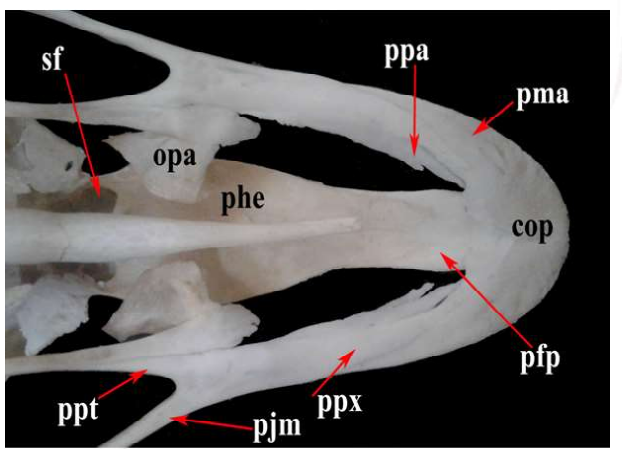

Int J Anat Res 2018, 6(2.3):5390-98. ISSN 2321-4287
Fig. 10: Dorsal view of ostrich skull with separated premaxilla showing: Proc. Frontalis (pff), Proc. Lacrimalis (pl), Os lacrimale (ola), lateral nasal process (Inp), Os premaxillare (opr), Proc. Maxillaries (pma), Proc. Frontalis (pfp), Proc. premaxillaris (ppm), Proc. Frontalis (pfn), Pars horizontalis ethmoidale (phe) and supraorbital fissure (sfi).

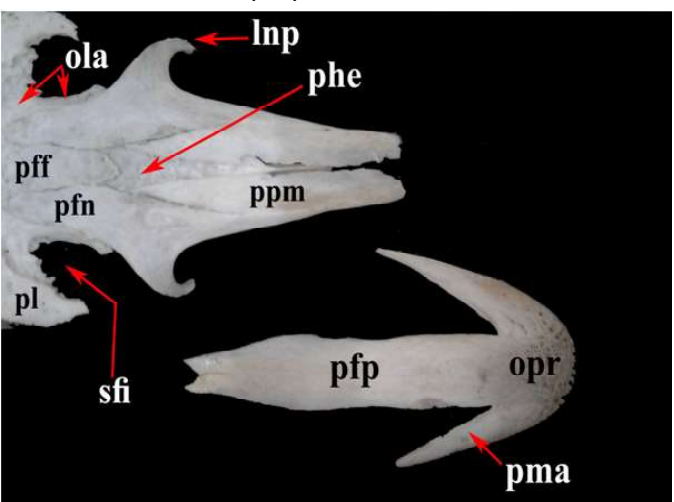

Fig. 11: Dorsal view of ostrich mandible showing: Symphysis mandibulae (sma), Os dentale (ode), Os angulare (oan), Os supra-angulare (osa), Os articulare (oar), Crista intercotylaris (ci), Proc. mandibulae (pmm), Cotyla dorsalis (cd), Cotyla medialis $(\mathrm{cm})$, Facies medialis (fme), Facies lateralis (fla), Foramin rostralis mandibulae (frm) and Foramin caudalis mandibulae (fcm).

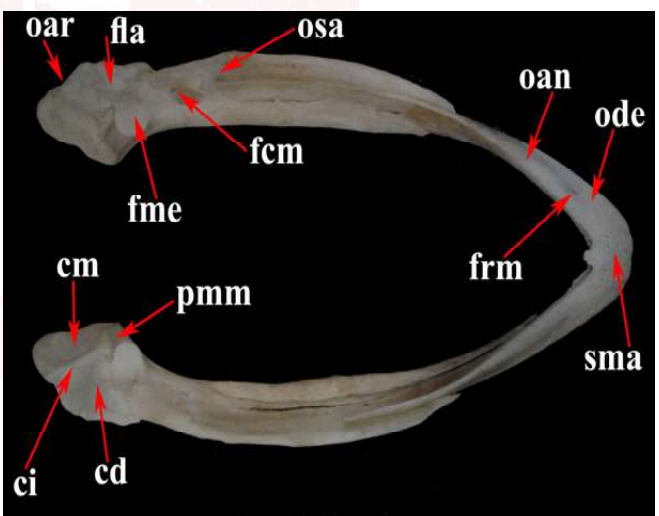

Fig. 12: Dorsal view of ostrich mandible (separated parts) showing: Symphysis mandibulae (sma), Os dentale (ode), dorsal and ventral delicate processes of angular bone (a), dorsal and ventral delicate processes of suprangular bone (s) and Os articulare (oar).

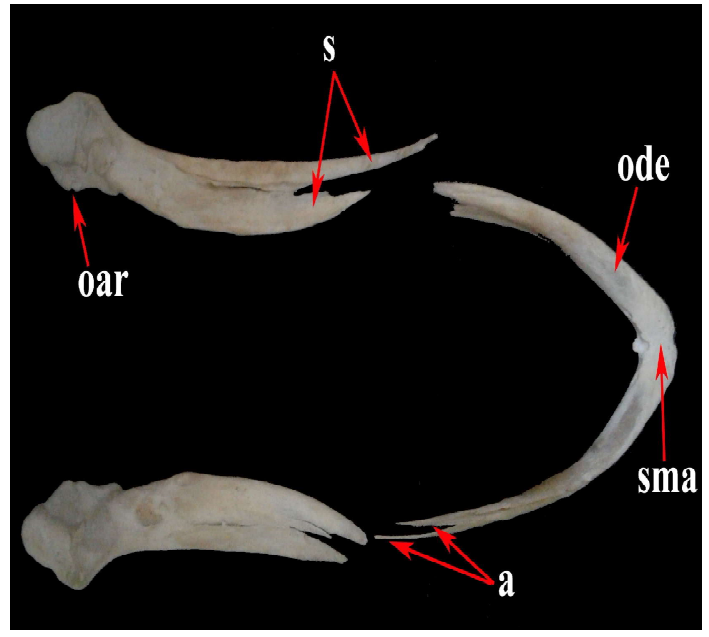


delicate bony plates. The horizontal part is located beneath and supported the nasal bones and the frontal process of premaxilla. The vertical one is separated between the orbital cavity caudally and nasal cavity rostrally. The latter shared in the formation of interorbital septum. The area between the two components contains a foreman for passing the ophthalmic nerve (orbitonasal or ethmoidal foramen) (Figs 7,8,9).

The parietal pneumatic bone is located nuchally in between supraoccipital bone distally and frontal bone rostrally (parietofrontal suture). It participates in forming of the surface of the cranial cavity and is compressed laterally by temporal fossa giving an origin to muscle temporalis (Figs1,2,7,8).

The frontal bone represents the major component of the surface of the cranium. It contains three surfaces, two borders and three processes. The external surface of both sides is slopped cranially and caudally and is raised centrally by frontal elevation, the internal surface has a deep cerebral fossa and the orbital surface (wing) forms the caudomedial limit of the orbit having a large optic foramen. The orbital surfaces of both sides are fused with each other, forming the interorbital septum. The lateral border represents the supraorbital margin while the medial borders are sutured with each other forming the interfrontal suture. The frontal bone is possessed frontal, lacrimal and postorbital processes. The frontal process is a transparent thin plate which roofed the frontal sinus and sutured with the frontal process of premaxilla. The supraorbital fissure is situated in between the lacrimal process, laterally and the lacrimal bone medially for lodging the lateral nasal gland. The postorbital process is over hanged the temporal fossa (Figs1,2,7,8,10).

The temporal bone forms of two parts; squamous part and ear capsule. The ear capsule has an irregular circular pneumatic cavity which is extended deeply, rostoventrally, until reaching the floor of the cranium and internally contains round narrow internal acoustic meatus. The capsule is demarcated by the squamous temporal bone laterally, basisphenoid, rostomedially and the lateral parts of occipital bone, caudomedially. The latter capsule is crossed transversaly by a cresentic groove called an orobasal articular groove which articulates with the otic process of quadrate bone. The squamous temporal bone has a large flat zygomatic process which is projected rostroventrally below the temporal fossa and lateral to the otic process of the quadrate bone. Both parts of the temporal bone share in the forming of the ventrolateral bony boundary of the cranium which having internally the shallow cerebellar fossa (Figs 3,4,5,6,7,8).

The quadrate bone takes the name from the shape. It consists of a body and three processes; mandibular, otic and orbital. The mandibular process is the most ventral largest one that divided by a deep groove into two medial and lateral condyles. The latter condyles articulate with the two medial and lateral facets on the dorsal cavity of the articular part of the mandible. The medial condyle is larger and more descends than the lateral one. Also, the mandibular process articulates with the pterygoid bone, medially and with the quadratojugal process of the jugal bone, laterally. The otic process of quadrate bone is embedded dorsally in between basisphenoid, ear capsule and squamous temporal bone, for articulation with the cresentic groove of the temporal bone. The orbital process is wide with free end that is projected rostomedially toward the orbit (Figs $3,4,56,8)$.

The lacrimal bone is small bone covers medially the frontal process of the nasal bone, demarcates the supraorbital fissure laterally and is fused caudally with the frontal bone. It has external smooth depressed surface and internal concave rough surface represents the lateral boundary of the frontal sinus (Figs $1,2,10)$.

The nasal bone is ceiled the nasal cavity and also sutures rostrally with the frontal process of premaxilla to form the upper beak. It is branched into three processes; frontal, premaxillary and lateral nasal. Frontal process lodges caudally in between the lacrimal bone laterally and frontal process of frontal bone medially. The premaxillary process prolongs rostrally below the frontal process of premaxilla. The lateral nasal one constitutes only the lateral bony 
boundary of the nasal cavity and not reaches to the maxilla (Figs 1,2,8,10). Premaxilla forms of the three processes which coalesce with the body rostrally giving the spear shape of the upper beak. The maxillary process begins thick, wide rostrally and tapered caudally fusing with the maxilla. The palatine process represents by a narrow thin plate of bone attaches and supports along its course the maxilla laterally and the palatine bone caudally. The palatine process of both sides unites with each other cranially enclosing a broad large cleft. The frontal process of premaxilla of both sides is sutured to each other covering the nasal bone which is directed caudally reaching the frontal bone forming nasofrontal hinge (Figs 1,2,3,4,8,9,10).

The maxillary bone is small, delicate bone constitutes the caudal rim of the upper beak and a part of bony palate, its rostral narrow part (premaxillary process) joins laterally with maxillary process of premaxilla and medially with palatine process of premaxilla. It is gradually broaden and branched caudally to fuse with pterygoid bone by pterygoid process of maxilla medially and form jugal process of maxilla laterally (Figs $1,2,8,9)$.

Zygomatic (jugal) bone is a thin rounded rod like prolongation of the caudolateral rim of the upper beak. Paired jugal bones diverges by curved manner caudally toward quadrate bone to form three fused bony parts; jugal process of maxilla bone, jugal and quadratojugal (Figs $1,2,3,4,6,8)$.

The palatine bone is a delicate quadrilateral bony plate present on both sides of vomer bone. It is joined with the posterior part of premaxilla and maxilla, rostrally while it overlaps the end of rostral pterygoid process, caudally (Figs $3,4,9)$.

The pterygoid bone is parallel thin quadrilateral delicate bony plates. It is placed on either side of vomer. It is directed caudally by short, thick like process (quadrate process) which joints and lodges in-between presphenoid medially and quadrate bone laterally. The other rostral long, narrow process (palatine part) fuses with palatine, maxilla and premaxilla (Figs $3,4,6$ ).
Vomer is a long tube like bone locates in the median plane of the floor of the skull. It has a narrow rostral end and wide caudal part which is fused with bars like processes of presphenoid. Along its course it grooved dorsally for including the nasal septum (Figs 3,4,7).

The mandible of the ostrich is nearly $V$ shaped with curved two Rami, which connects rostrally forming wide mandibular symphysis and converges with each other caudally. It consists of four fused parts; dentary, angular, supra angular and articular parts. The dentary bones of either side are connected rostrally to adapt the shape of the upper jaw and form the mandibular symphysis, distally. It has numerous lateral and medial rostral mandibular foramina. The angular bones are bounded the dentary bones caudolaterally, which bifid caudally giving dorsal and ventral delicate processes. The supra angular part fuses caudally with articular part of mandible and rostrally intercalates by two dorsal and ventral delicate processes, with the two processes of angular bone. The dorsal process of supra angular bone is directed outward while the ventral one is directed inward. It has an outward dorsal border and inward directed ventral one. It contains flat lateral surface and grooved rough medial one. The lateral and medial surfaces have caudal mandibular foramina. The articular part constitutes caudal part of the mandible which looks prismatic in shape. It is splited into irregular deep dorsal articular cavity and a shallower medial ovoid muscular one being distinguished from each other by a bony plate. The latter is directed rostomedially forming, a process (mandibular process) for attaching the ligament and joint capsule of quadratomandibular joint and projects caudally by a blunted angle. The dorsal articular cavity is congruent and articulates with the mandibular process of the quadrate bone by two medial and lateral facets forming quadratomandibular joint (Figs 11,12). The hyoid consisted of bones and cartilaginous parts associated with upper respiratory system forming the hyobranchial apparatus.

The bony nasal cavity is the smallest cavity in the ostrich skull bounded dorsally by the nasal bone, frontal process of premaxilla and horizontal 
plate of ethmoidal bone. Dorsolaterally, it is limited by the lateral process of the nasal bone. The ventral boundaries from rostral to caudal are the maxillary and palatine processes of premaxilla, maxilla, palatine bone and the rostral part of pterygoid bone, respectively.

The two right and left halves of the nasal cavity are completely separated by an osseous nasal septum (Figs $2,7,8$ ). The nasal septum projects rostrally till termination of the vomer and fuses caudally with the vertical part of ethmoid and the interorbital septum. The nasal septum is supported dorsally by the horizontal plate of ethmoid and nasal bone, while it is lodged ventrally on the dorsal aspect of the vomer (Figs7,8).

The bony boundaries of the ostrich cranial cavity are the frontal bone, dorsally; basioccipitale and basisphenoid, rostoventrally; the parietal and supraoccipital part, caudally and posterior part of interorbital septum, rostrally while the lateral aspect is temporal bone. Internally, it is divided by a transverse crest into upper large, deep cerebral fossa and lower small shallow cerebellar fossa. Distally it has maxillomandibular foramen (Figs $2,7,8$ ). The large cavity in ostrich skull is the orbital cavity. It is incomplete orbit that is roofed by the frontal bone, bounded ventrally by the pterygoid and jugal bones, medially by the frontal bone and interorbital septum, rostrally by the vertical plate of ethmoidal bone and caudally by the frontal bone, temporal fossa, squamous temporal bone and quadrate bones (Figs 2,7,8).

Right and left frontal sinuses are the bony paranasal sinuses in ostrich skull that is located in between the nasal and cranial cavities. At the median plane, they separate from each other by a thin bony plate. It is bounded dorsally by the frontal process of the frontal bone and laterally by the lacrimal and the vertical plate of ethmoidal bone. It is pierced by paired olfactory foramina connecting it with the cranial cavity, but communicating rostrally by a wide oval foramen to the nasal cavity (Figs $3,4,7,9$ ).

\section{DISCUSSION}

The obtained results correlate with that reported by $[7,8]$ the neurocranium of large birds as ostrich appears small size and this finding may reflect the largest orbital cavity. Notably, the occipital bone in ostrich has a rounded Foramen magnum that is situated basally which similar to pigeon skull and unlike duck and goose which vertically directed in the grey heron $[4,7,8]$. In contrary to that mentioned by [9] in emu, there is a pear shaped occipital condyle. Moreover, the paired lateral part of occipital bone has a broad like process which attached distally by a ligament to the articular part of the mandible that is conflicted with [9], that noted the exoccipitale articulated with the mandible. Parallel to [8] in fowl and [9] in emu, the same bony parts of sphenoid bone except [8] in goose and duck mentioned that basispenoid has distinct muscular processes and grooves. However, [9] added well developed mandibular processes were present at the junction of basisphenoid and presphenoid.Surprisingly, the ethmoid did not participate in the formation of neurocranium. The latter completely agreed with that reported by $[8,9]$. Although a little difference in the present work conflicted with [9] that the ethmoid bone located under the frontal bone and also with [10] that noticed in crow that the horizontal part was reduced.In contrast with $[8,9]$ that recorded that the frontal bone possessed frontal, orbital and nasal processes, meanwhile, this study agreed with that revealed by [11] in goose. It is of great importance to know that, the present investigation and [9] revealed no orbital process of temporal bone. On the other hand, [8] introduce an orbital process of the squamous temporal bone above the temporal fossa, which is stout and long in duck and geese, more slender in fowl and rudimentary in pigeons. The latter authors added that the orbital process in fowl fused with the zygomatic process of temporal bone.Unlike [9] that reported there are frontal, lacrimal and cranial processes of lacrimal bone that formed the cranioventral margin of the orbit. In the same line with [8] that added there was a small lacrimal bone in fowl and pigeon and large in duck and geese, but the present study revealed no movable joint between the lacrimal and nasal bone.Similar to $[12,13]$ in ostrich and [14] in Baryphthengus ruficapillus, the same structures and articulations of the quadrate bone were noticed. However, different result was cleared by [9] who clarified that, the otic process articulated with the zygomatic process 
of temporal bone, a lateral process articulated with jugal bone and the orbital process was just like a bulla which was broad with oval free end. A variable finding is noted by [4] in grey horn added that the quadrate bone has three condyles articulate with the mandible. It is also interesting to know that $[8,11]$ in goose detected that the lateral nasal process of nasal bone don't reach and fuse with the maxilla, meanwhile the opposite observations found in fowl $[8,11]$ and [9]. Regarding the premaxilla of ostrich, [9] in the emu and [8] in fowl and pigeon reported no variation in the current study that, there is a broad cleft of palatine process of premaxilla otherwise in duck and geese [8, the two Palatine processes on both sides fused medially forming a plating palate which has a short narrow slit like opening. The present work conflicted with $[8,9]$ that revealed a connection of maxilla with nasal bone. The shape of palatine bone in fowl and pigeon is rod like that differs from the present research, but similar with duck and geese [8].

The vomer is rudimentary in fowl and pigeon [8] thus completely differ with the current observation. The latter may contribute to flight regarding.The descriptions of bony nasal cavity and nasal septum go hand to hand with [15] in ostrich. The obtained results of the bony boundary of the ostrich cranial cavity was nearly similar with [11]. Dissimilar to $[16,17]$ in fowl that the roof of the cranial cavity formed by the frontal, parietal and supraoccipital bones. The ostrich mandible is a nearly $V$ shape with two Rami, which jointed rostrally forming wider mandibular symphysis that is correlated with that revealed by [18] in the the rock pigeon. Recently, [9] reflects the same result that the mandible of emu having angular, articular, supra angular and dental parts. Even though, [11] in fowl and [18] in the rock pigeon added that, there are five parts of mandible; splenial, angular, supraangular, articular and prearticular. Moreover, [8] in fowl recorded six parts; articular, angular, supra-angular, complementary, opercular and dental. Really, the angular part of mandible in this investigation has dorsal and ventral processes which are projected caudally, that conflicts with [9] who reported a medial process which directed forward and outward whereas the lateral process directed inward.In agreement with [9], [19] in the hooded crow and [12] the articular process is divided into two facets; medial larger facet and smaller lateral one. Furthermore, [19] in the cattle egret found three medial, lateral and caudal facets.A Significant result is obtained in this work that the skull of the ostrich is similar to domestic birds almost to duck and geese rather than fowl and pigeon skulls.

\section{CONCLUSION}

As general of birds, the bony head in ostrich contains two groups of bones neurocranium and splanchnocranium and there is no interparietal bone. A significant result was obtained in this work that, there are variations in shape and components of ostrich skull bones in comparison with other birds. The similarity to small domestic birds was almost near to duck and geese rather than fowl and pigeon skulls. Also, there are some variations with large birds like an emu. These differences might be due to the different patterns of feeding behavior.

\section{ACKNOWLEDGEMENTS}

This research was supported by the department of anatomy and embryology, faculty of veterinary medicine. Zagazig University. We thank the department of surgery in our faculty, especially Dr, Ahmed Moneur Assistant lecturer of surgery for the kindly assistance in X-ray scan preparation.

\section{Conflicts of Interests: None}

\section{REFERENCES}

[1]. Jamroz D. Feeding ostriches and emus: physiological basis and nutritional requirements a review. Prace Materialy Zootechniczne .2000; 56:51-73.

[2]. Mushi E Z, IsaJ JFW, Chabo RG, Segaise TT.. Growth rate of ostrich (Struthio camelus) chicks under intensive management in Botswana. Trop. Anim. Health Prod. 1998; 30: 197-203.

[3]. Pop C, Pentea M. The osteological features of the skeleton in ostrich (struthio camelus). Lucrãri Stiin $^{3}$ ifice Medicinã Veterinarã, Timisoara. Calea Aradului vol. xl; 2007.

[4]. Atalgin ${ }^{a} \mathrm{H}$, Buyukcopur EUB, KuRuL I. A detailed evaluation of the skeletal elements of the skull in the grey heron (Ardea cinerea). Turk J Vet Anim Sci. 2014; 38: 370-376.

[5]. Leite AGB, Silvério LMGS, Silva GMD, Araújo AGS, Oliveira D. Anatomical description of the skeleton of ostrich (Struthio camelus): case report. Biotemas. 2012; 25: 193-200. 
[6]. Nomina Anatomica Avium. International Committee on Avian Anatomical Nomenclature, a committee of the World Association of Veterinary Anatomists, $2^{\text {nd }}$ Edition, Cambridge, Massachusetts; 1993.

[7]. Dyce KM, Sack WO, Wensing CJG. Textbook of Veterinary Anatomy. 3rd Ed. Saunders, Philadelphia, London, New York, St. Louis, Sydney, Toronto; 2002:789791.

[8]. Nickel R, Schummer A, Seiferle E. Anatomy of the Domestic Birds, chapter (skeleton of the head), Verlag Paul Parey, Berlin and Hamburg; 1977 :2025.

[9]. Kumar P, Singh G. Gross Anatomy of Axial Skeleton in Emu (Dromaius novaehollandiae). Indian Journal of Veterinary Anatomy. 2014; 26 (2): 87-91.

[10]. John MA, Baba MA, Khan M, Sasan JS.: Anatomical Studies on the Skull of Crow (Corvus splendens) Article in International Journal of Scientific Research. 2016; 5-(2):189-193.

[11].Feduccia A. Aves Osteology. In Sisson and Grossman's. The Anatomy of the Domestic Animals, 5th Ed. R., Vol. 2, W.B. Saunders Company, Philadelphia, London \& Toronto; 1975: 1790-1794.

[12]. Ali S. Some Morphological Studies on the Quadratomandibular joint of Ostrich (Struthio camelus). Benha veterinary medical journal. 2015a; 29 (2): 319-325.
[13]. Imam HM, Elmahdy OM. Some anatomical studies on the quadratomandibular articulation of ostrich (Struthio camelus) and Flamingo (Phoenicopterus ruber). Assiut Vet. Med. J. 2004; 50: 1-20.

[14].Pascotto MC, Donatelli RJ. Cranial Osteology in Momotidae (Aves: Coraciiformes). Journal of Morphology. 2003; 258: 32-48.

[15]. Ali S. Gross Anatomical Studies on the nasal cavity of the ostrich. Benha veterinary medical journal. 2015b; 29 (2): 326-332.

[16]. King AS McLelland J. Birds, their Structure and Function. Bailliere Tindall, London; 1984.

[17]. McLelland J. A color of atlas of avian anatomy" Wolfe Publishing Ltd; 1990.

[18]. Proctor N, Lynch P. Manual of ornithology: Avian structure and function. New Haven: Yale University Press; 1993.

[19]. Hassan SA. Comparative Morphological Studies on the Quadrato-mandibular Articulation in Hooded Crow (Corvus cornix) and Cattle Egret (Bubulcus ibis). J. Vet. Anat. 2012; 5 (1)3 -46.

How to cite this article:

Attia A.A. Moselhy, Sherif Kh. A. Mohamed, Hanaa M. El-Ghazali. ANATOMICAL FEATURES OF BONES AND BONY CAVITIES OF THE OSTRICH SKULL (STRUTHIO CAMELUS). Int J Anat Res 2018;6(2.3):5390-5398. DOI: 10.16965/ijar.2018.213 